\title{
Human Resource Development Level and Its Interconnection with Regional Economic Situation
}

\author{
Shishkina N.V.* \\ Chair of Economics and global economy \\ Voronezh state agrarian university \\ Voronezh, Russia \\ e-mail: natalia.schischkina@yandex.ru
}

\author{
Sabetova T.V. \\ Chair of Management and marketing in AIC \\ Voronezh state agrarian university \\ Voronezh, Russia \\ e-mail: tsabetova@mail.ru
}

\author{
Lyubavskiy I.N. \\ Chair of Economics and global economy \\ Voronezh state agrarian university \\ Voronezh, Russia \\ e-mail: mr.lyubavskiy@ mail.ru
}

\begin{abstract}
In this paper, we consider the components that characterize the essence of human potential and a system of indicators reflecting the influence of the level of its development on the state and effectiveness of the socio-economic system of the region. Based on the analysis of empirical data for the Voronezh region, the assumption about the mutual influence of the level of human development and the economic results of the functioning of regional systems is verified. For this purpose, the authors used the characteristic of such pairs of indicators as GRP per capita the number of economically active population; GRP per capita income per capita; GRP per employed in the economy $\leftrightarrow$ nominal wage; average life expectancy $\leftrightarrow$ number of doctors per 10,000 population; life expectancy $\leftrightarrow$ per capita income; GRP per capita $\leftrightarrow$ number of students in higher education organizations. The authors concluded that this assumption is in place, but not to the extent that was originally thought.
\end{abstract}

Keywords - wages, socio-economic development region the level of human potential, human potential quality, indicators, GRP per capita, number of econbomically active population.

\section{INTRODUCTION}

An economic attitude to the concept of efficiency usually creates a starting point for calculations of productivity with a monetary value [1]. When analyzing country or regional economies, the researchers use gross value added or gross domestic product to reveal outputs from the engaged resources, including human resources.

The economic category 'labor potential' was introduced in the 1970s to express a general assessment of personnel, taking into account not only its actual characteristics, but also reserves and potential opportunities. The most widely interpreted, the labor potential of a company is understood to be the ability to make the required contribution to the implementation of the company's objectives, based on professional knowledge, practical skills, personal and psychophysiological characteristics of employees, in case of the proper material, technical, informational and organizational support for the labor process.
The labor potential is described by a total of components including:

- Quantitative components, such as number of employable population; number and structure of the employed defined based on various characteristics; population structure in terms of sex and age; loss of working hours due to illnesses or disciplinary problems, etc.

- Qualitative components, which include but are not limited to educational level; professional skill development level; general knowledge; health condition; personal features; motivation; responsibility; professional growth, etc.

To assess the human resources or the human potential of the region, it is always a matter of priority to select the most appropriate and reliable indicators for performing diagnosing at the required level of research, which in our case is the regional level.

It is important to emphasize that if we examine the human potential of the region, then in this analysis it is quite acceptable to take into account the various indicators that describe the entire population, not only its economically active part. This is due both to the obvious fact that significant part of the population, currently unrelated to labor resources, will become such in the foreseeable future and add their characteristics to the labor potential of the territory (young generation is entering the employable age; disabled people under certain circumstances can be employed and effectively support themselves as well as add to the gross regional product), but also to other, less obvious circumstances (for example, the health condition of grandparents greatly affects the labor activity of the parents and sometimes also the development of the general knowledge of the children). 


\section{SELECTION OF THE INDICATORS FOR HUMAN POTENTIAL ANALYSIS}

The choice of indicators for describing the human potential of the region should meet the principles of complexity and representativeness. The principle of complexity means the fullest possible coverage of all the most important systems for the formation of human resources in the region with the selected indicators. The principle of representativeness suggests the selection of indicators from the point of view of their materiality for the development of human potential in general.

However, in no way challenging the importance of these principles, we are forced to point out the current situation. It is such that an independent researcher or analyst, who wants to study the condition of the human potential of a region or a country, or some of its parts and aspects, faces deficit of information virtually impossible to overcome. Most often, he is forced to rely only on official statistics and, at best, on his own observations, surveys and research. A significant part of the indicators that seem to him essential from the point of view of the principle of complexity, in this case, is beyond his reach: they are either not available at the regional level of statistics, or are not collected by the Federal State Statistics Service in general.

A large number of indicators, the application of which is possible under certain conditions and for different purposes of the study, require their classification based on various grounds. From the point of view of quantitative evaluation, the most important basis for classification is the quantitative measurability of the indicators. Meanwhile, we propose, in addition to countable and non-quantifiable, to allocate quasiquantifiable indicators.

A wide range of indicators are generally used to reflect the influence of the socio-economic system of the region on the formation and quality of its human resources, for example:

- GRP per capita / per capita of labor resources;

- per capita income;

- the ratio of the acquisition of goods and services in the structure of expenditures of the population;

- nominal and real incomes of the population;

- unemployment rate;

- availability of basic goods;

- incidence rates;

- educational level and many others.

However, for the purposes of our research, it is important to choose not a one-sided but a mutual dependence (or, on the contrary, a lack of correlation) between indicators of the quality of labor resources and indicators characterizing the system of its formation and maintenance. It is also important to emphasize that absolute proportions between these indicators cannot be identified even theoretically. Therefore, to determine the relationships it is necessary to analyze the dynamic series. In our opinion, the main relations for analysis should include:

- GRP per capita $\leftrightarrow$ the number of labor resources;

- GRP per capita $\leftrightarrow$ per capita income;

- GRP per one employed in the economy $\leftrightarrow$ average monthly nominal wage

- Average life expectancy $\leftrightarrow$ per capita income;

- Average life expectancy $\leftrightarrow$ number of doctors and nurses per 10,000 of the population

- GRP per capita $\leftrightarrow$ number of students in primary, secondary vocational, higher education institutions per 10,000 population;

- GRP per one employed in the economy $\leftrightarrow$ the share of the employed with certain levels of education.

The size of this paper does not allow considering all the available proportions, but we will focus our attention on some of them, analyzing them for the Central Black-Soil region. In this article we will give information on the Voronezh region, but calculations were carried out for other regions as well. Since the earlier analysis [4] proved the comparative wellbeing of this particular region, it is logical to assume that these combinations of parameters will also manifest themselves in the most favorable manner.

\section{ANALYSIS OF THE INDICATOR CORRELATIONS}

Naturally, we can consider a lot of other proportions, but these are available from the national and regional statistics and therefore are verifiable.

\section{A. GRP per capita $\leftrightarrow$ the number of economically active population}

So, first of all we address the pair of indicators 'GRP per capita $\leftrightarrow$ the number of economically active population'. Their comparison for Voronezh region is demonstrated in Fig.1. We should note that henceforth the indicators are presented in unusual units for better visualization of the charts.

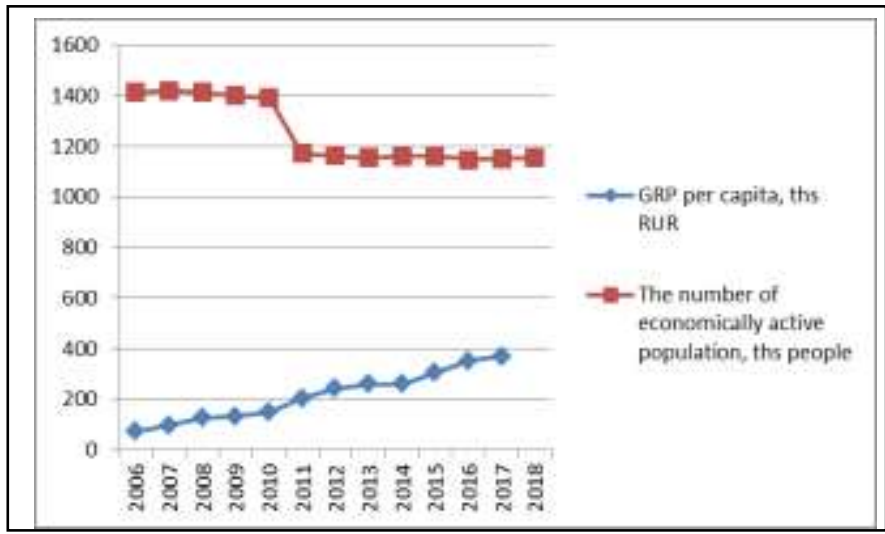

Fig. 1. The comparison of the dynamics of the pair of indicators 'GRP per capita $\leftrightarrow$ the number of economically active population', Voronezh region (based on [5]) 
As we see, GRP per capita demonstrates a constant and almost continuous growth, albeit at different rates. The introduction of the correction for the inflation rate practically does not change the trend, although it slows the growth of the curve.

Theoretically, it is possible to assume any kind of connection in this pair of indicators. On the one hand, the growth of GRP per capita could lead to a decrease in the economy's need for human resources, and consequently, to increase the opportunities for part of the population to move into a group that does not want to find work, for example, house wives, students, etc. On the other hand, to some extent more effective work is attractive for the workers themselves, and therefore can stimulate more people to join or strive to join in labor activity.

Meanwhile, the curve of the number of economically active population does not correlate in any way with the dynamics of GRP. Moreover, the former does not demonstrate either rapid or stable positive dynamics.

Consideration of the possibility that GRP per capita correlates not with the number of economically active population, but with the number of the employed, also received no statistical confirmation. Hence, we conclude that the values of the number of both economically active and, in particular, the employed population depend much more on demographic reasons than on economic ones. Meanwhile the regional and national economies are forced to adjust to the available amount of human resources. However, even here there is no direct adjustment through the price of the labor the wages, even real wages, increase almost constantly, while the number of employees is fluctuating. The periods of reduction of real (not nominal) wages correspond to critical moments of the economic development, without the slightest association with the dynamics of the number of the employees.

Consequently, it can be assumed that the regional economy is able to cope with the normal, within demographic patterns, fluctuations in the number of economically active population. Only large-scale rare or unique social events can rip it out of its normal functional mode and lead to unfavorable changes such as (i) changing the role of women in society (as it was when women began to work massively in public production); (ii) drastic changes in the age limits of the employable population, for example, raising the retirement age by 5 or more years; (iii) large influx of migrants or refugees, etc.

\section{B. GRP per capita $\leftrightarrow$ per capita income and GRP per one} employed in the economy $\leftrightarrow$ average monthly nominal wage

Nest we considered the pair of indicators 'GRP per capita $\leftrightarrow$ per capita income' (Fig.2) and the pair 'GRP per one employed in the economy $\leftrightarrow$ average monthly nominal wage' (Fig. 3).

In this case, naturally, the question arises not about the same direction of the dynamics of these indicators. It is quite obvious that the dynamics will be constantly rising, especially if we take into account that both indicators are taken in the nominal rather than the real dimension (we have the right to do so, since the inflation rates are determined for the whole economy and have the same effect on GRP and on wages, and social payments to citizens).

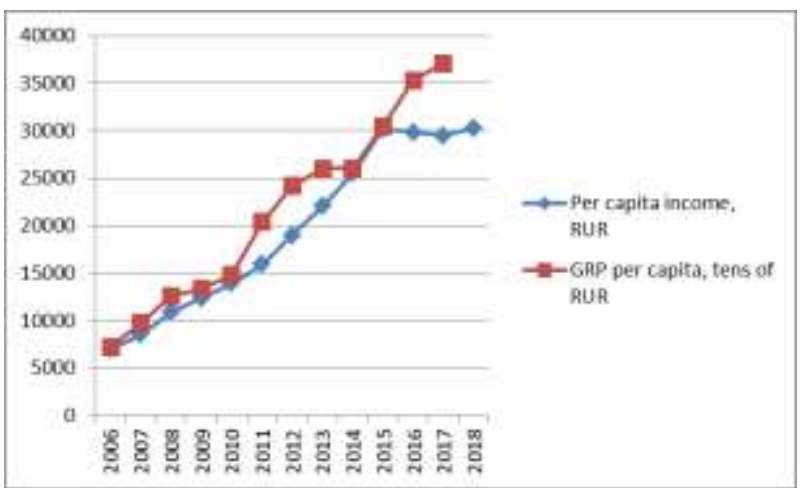

Fig. 2. The comparison of the dynamics of the pair of indicators 'GRP per capita $\leftrightarrow$ per capita income', Voronezh region

A much more interesting fact seems to us that for all five regions of the Central Black-Soil area, including Voronezh region, we see fluctuations in the GRP per capita: then a sharp enough growth, then a slowdown in dynamics. Meanwhile, the curve for the income of the population is much more even, we might say - not a curve, but an almost direct rising line, if not for the fall in nominal incomes started from 2016.

To a certain extent, such situation seems to us a positive circumstance, moreover, a sign of the social orientation of the state. Correlation, in our opinion, should be more pronounced in the pair 'GRP per one employed in the economy $\leftrightarrow$ average monthly nominal wage'. The function of governmental social protection is to mitigate income fluctuations during periods when GDP (GRP) growth slows down, and logically, labor remuneration ceases to grow or even decreases. Compensation occurs at the expense of income growth of those members of households that have the right to receive certain social benefits, and in general for the population the situation is leveled. Accordingly, preventing the decline in aggregate and average incomes of the population serves the preservation of the purchasing power of the population, thus stimulating demand and economic development, and after a while - and GDP (GRP) growth.

However, if such understanding of the situation is true, then the dynamics in the pair 'GRP per one employed in the economy $\leftrightarrow$ average monthly nominal wage' should be much more similar [6, 7]. Meanwhile, in Fig. 3, we do not observe this similarity in the shape of the curves, either simultaneously or with a delay.

Firstly, the curves of wage changes are also close to linear shape, as wee as the income level curves in general, and there are no differences for studied Voronezh region. This leads us to the idea that wages currently act as rather a social than an economic indicator. This, in its turn, causes the following circumstances:

- Disruption of the conditions for the manifestation of economic laws and patterns; 
- Complete elimination of the wages function associated with the stimulation of labor activity and its quantitative and qualitative characteristics;

- Reduction of the gap in income of working and nonworking people, i.e. the wages do not form the desire for employment.

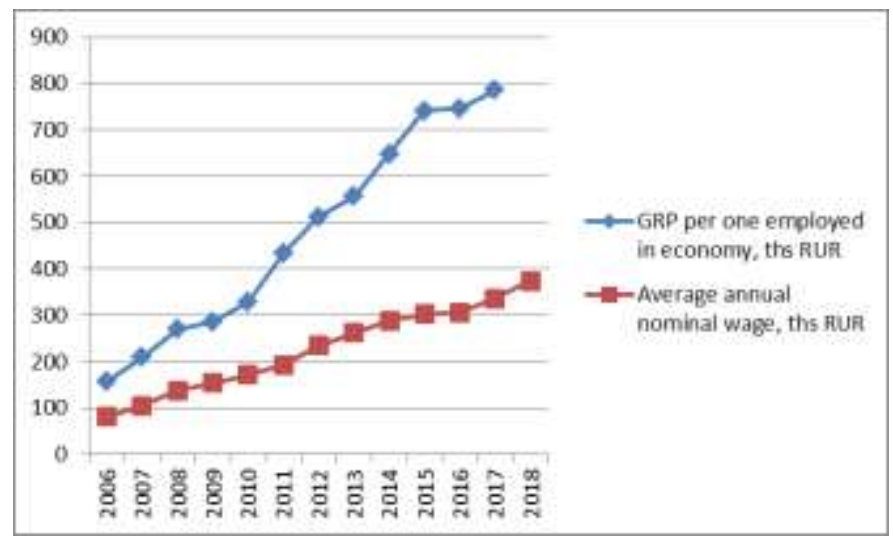

Fig. 3. The comparison of the dynamics of the pair of indicators 'GRP per one employed in the economy $\leftrightarrow$ average annual nominal wage', Voronezh region

As a result, it can be argued that the hypothesis proposed above concerning the governmental mitigation of salary fluctuations due to social payments is not confirmed in any way. On the contrary, it seems that there is no need for such actions on the part of the state, since wages have already been levelled compared to the dynamics of the economic development as a whole. This significantly understates the role of governmental social support in a society which, in essence, comes down only to ensuring the survival of most poor citizens, but does not make economic sense.

To some extent, this phenomenon can be explained by the huge share of the so-called 'budgetary employees' (employees within the state organizations) among the employed population. According to some estimates, the share of people whose work is directly or indirectly financed from budgets of different levels, reaches $50 \%$ of the employed in the economy $[8,9]$. These persons are hired by the state, which traditionally more often solves issues of social support through wages, rather than issues of improving the efficiency of its structural units. However, if there was only the influence of the share of those employed in the public sector, the levelling would not be so complete and obvious.

Secondly, we cannot ignore the somewhat sharper overall increase in GRP per employee. During the whole considered twelve-year period this indicator grew by approximately 5 times, while the salary increased only 4 times. It is known that the recommended dependence of the wage growth in a company compared to labor productivity is described by the ratio ' $1 \%$ of the increase in labor productivity should cause $0.5 \%$ of the increase in wages'. In this case, for every percent of GRP growth for each employed citizen, an average of $0.87 \%$ of the increase in labor remuneration was achieved. At the same time it should be taken into account that the GRP per employee is not a direct analogue of the labor productivity indicator, because apart from labor effort it depends on a number of other parameters, in particular, on the use of invested capital.

Such ratio, of course, is to some extent caused by the 'low base effect', since the labor remuneration in our country and in the regions of the Russian Federation we are considering were and even now remain relatively low. However, this consideration once again confirms the predominance of the social function of wages in our region and the country as a whole.

The discovered absence of an economic function in the labor remuneration leads us to yet another conclusion directly related to the problem we are investigating. The employees whose wages are deprived of economic reason will not be inclined to take any action to improve their labor performance, i.e. they will neither make more efforts in the work here and now, nor spend time, energy and resources on professional self-development [10]. The principle 'each gains according to his needs', no matter how attractive it might be from a humanistic point of view, in no way stimulates the realization of the principle 'each gives according to his abilities' [11]. Moreover, those abilities themselves can cease to develop or even degrade if long neglected or disused.

The authors do not aim to protest the need to level out the impact of purely economic processes on the population, but stress that if such levelling is not carried out at the expense of certain forms of social income (dissociated from labor remuneration), but at the expense of wages, the latter may lose their stimulating function.

It should be pointed out that at the company level such situation does not appear to us negative or even alarming, since there labor stimulation remains materially substantial, but the incentive function is shifted to bonuses and other payments. However, at the national or regional level, we consider labor remuneration in its statistical sense, i.e. as the sum of all payments related to the employment and labor activities of the population, without division into salaries, bonuses, benefits, allowances and so on.

We recognize the possibility that each specific employer differentiates employee benefits depending on the results of their work, which, in theory, should be an incentive for each individual to grow generally and professionally. However, given that in the society in general the influence of such differentiation is not felt, it is reasonable to assume that different employers carry out their wage policy based on different principles. Therefore, on average, it turns out that one employee gets bonuses or additional payments based on the results of work, while the other - for example, in a different organization - without any connection to his performance or professional achievements. As a result, part of the labor resources will strive to develop and improve, while the other part - just to change the place of work, and the third part - to nothing at all.

Meanwhile, if the state policy does not aim to push changes in the principles of wage formation in one way or another, the authorities should offer the society other incentives for the development of its labor potential: perhaps, moral, ideological or some others. 
C. Average life expectancy $\leftrightarrow$ number of doctors and nurses per 10,000 of the population and average life expectancy $\leftrightarrow$ per capita income

We also believe that it is important to consider the influence of various factors on such parameters of the regional human resources as life expectancy and health, and also the role of these parameters in the formation and maintenance of the characteristics of human resources. As an example, we considered the life expectancy and two factors that, in our opinion, can influence it: income level and the number of doctors.

We demonstrated the pair of indicators 'average life expectancy $\leftrightarrow$ number of doctors and nurses per 10,000 of the population' in Figure 5.

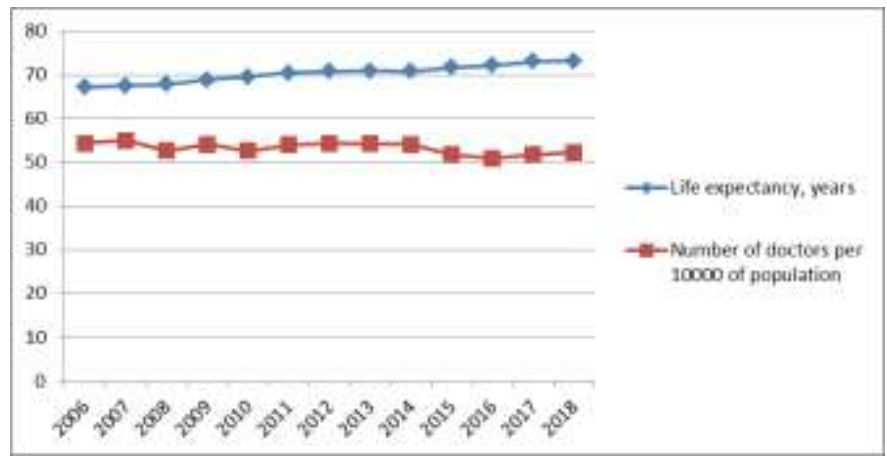

Fig. 4. The comparison of the dynamics of the pair of indicators 'average life expectancy $\leftrightarrow$ number of doctors and nurses per 10,000 of the population', Voronezh region

The life expectancy has increased, but its dynamics is not related to the number of doctors. The latter fluctuated throughout the period. As a result, the number of doctors per 10,000 of population decreased by almost $4 \%$ during the period from 2006 to 2018 in Voronezh region.

It is logical to assume that the number of doctors can not have an immediate impact on the average life expectancy, but the total lack of correlation for more than a decade is already revealing.

The authors cannot ignore the fact that the number of doctors is almost unrelated to the amount of medical services rendered to the population. It's no secret that at the present time a significant percentage of medical staff at all levels and specialties have employment in more than one organization and more than one wage-time. In private medical organizations, as well as, partly, in designated institutions, there are very few staff members (especially in the former), for whom this job is the only one. As a result, the same number of doctors can provide very different amounts of medical services. A home question is how such employment affects the performance, professional development, and even the health of the doctors themselves. But for the purposes of our research, the quantitative indicators matter. Statistics accounts for the medical services by the number of medical institutions irrespective their size; by the number of doctors and nurses irrespective the degree of their work load; on the number of beds irrespective their occupancy. Even the statistics of morbidity, in our opinion, does not characterize the success of healthcare and, moreover, cannot be a qualitative characteristic of human resources, since diseases are not always detected and not always cured. As for prevention issues that have the most direct impact on human potential, they are virtually not represented in regional statistics.

Thus, the observed increase in life expectancy is probably influenced by some other factors. Among the factors of the economic nature, one can name the influence of the population's incomes, employment, income distribution and some others. We compared the dynamics of a pair of indicators 'average life expectancy $\leftrightarrow$ per capita income' (Fig. 5).

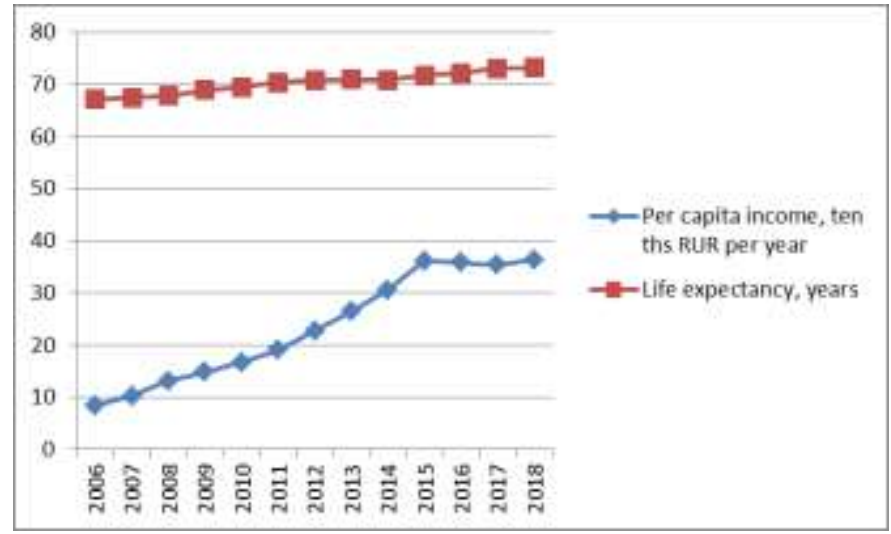

Fig. 5. The comparison of the dynamics of the pair of indicators 'average life expectancy $\leftrightarrow$ per capita income', Voronezh region

As we see, the general orientation of the dynamics of the two indicators is the same. However, if we consider the statistical data of the Voronezh region, then the sharpest jumps in income were recorded in 2008, then in 2012, and then in 2015. In the average life expectancy, the increases in 2009 , and then in 2011 are noticeable.

Hence we can make two assumptions. One is that despite the similarity in the shape of the dynamic series, these indicators are unrelated and have no effect on one another. Second is that income represents strong but far from the only factor determining the average life expectancy, but this factor is acting with a small delay, which is more likely.

\section{GRP per capita $\leftrightarrow$ number of students in higher education institutions}

Finally, in our opinion, there should be some correlation between the formation of GRP and the quality of human potential, including its the educational level $[12,13]$. To identify the presence or absence of such connection we considered the dynamics of a pair of indicators 'GRP per capita - number of students in higher education institutions', as these data are the most easily available from the statistical information (Fig. 6).

Presumably, these parameters should be interrelated: graduates, by virtue of their qualifications, are able to produce more products than people without education, and a richer economy, in turn, stimulates people to self-development, and its employers to encouraging the professional growth of their employees [14]. 


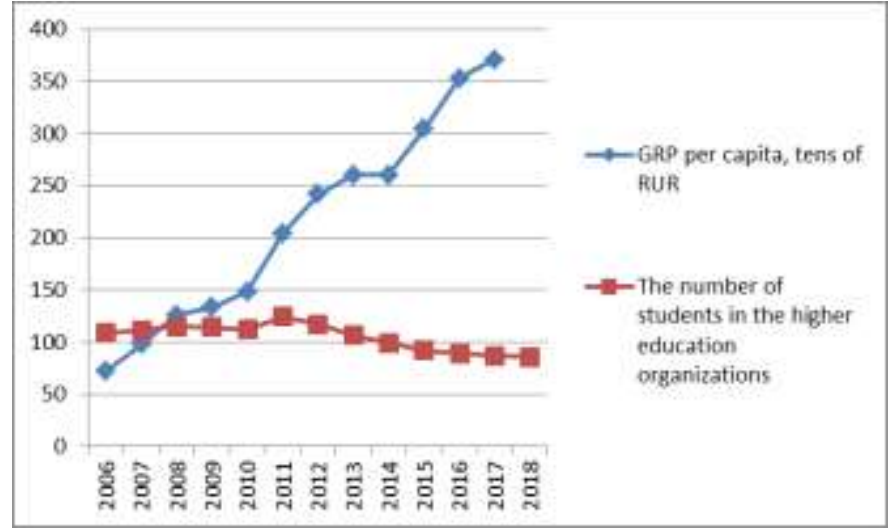

Fig. 6. The comparison of the dynamics of the pair of indicators 'GRP per capita $\leftrightarrow$ number of students in higher education institutions', Voronezh region data.

However, no such correlation is found from the statistical

The changes in these indicators are opposite, and in Voronezh region the reduction in the number of university students occurred gradually and even not permanently, unlike many other regions of the Russian Federation including the other regions of the Central Black-Soil area, such as Belgorod and Tambov regions. On the other hand, GRP per capita for the ten-year period in the Voronezh region increased by $414 \%$, while, for instance, the growth of Belgorod's GRP is more than $50 \%$ less. So, perhaps, there may take place this longterm and delayed effect that can be expected in this pair of indicators.

\section{CONCLUSION}

Thus, following the results of the study, we draw the following conclusion. Although there is certain mutual influence between the statistically fixed parameters of the quantity and quality of human resources and the economic results of the regions, it is not as obvious and straightforward as we originally supposed. The influence of different parameters is superimposed on each other; some of them exert a delayed action. A part of the hypothetical relationships has not been proven at all.

Further researches, based on statistical data, direct observations, and niche surveys are required for identifying the particular social and economic factors that have the most pronounced effect on the human potential of a territory, and vice versa, the human potential features affecting the economic results of the territory of its residence and employment.

\section{References}

[1] M. Cyrek, 'Social efficiency of employment in three sectors - a comparison of Polish regions," Equilibrium. Quarterly Journal of Economics and Economic Policy, vol. 12, no. 3, pp. 417-432.

[2] D.Yu.Rudenko, A.B.Tilimbaeva, 'Assessment of the interconnection between the investment in human capital and social and economic development level of the countries in the world', Bulletin of Tumen state university, 2013, no. 11, pp. 20-30.

[3] T.V. Sabetova, "The prospects of the qualitative parameters of the human potential," Labor standards and wages in industry, 2014, no. 7, pp. 46-52.

[4] T.V. Sabetova, N.M. Shevtsova, Interrelation between the human capital development level and the social and economic development of a region, Monograph. Voronezh, 2018.

[5] The official website of Russian National Statistical Service. Retrieved from: www.gks.ru.

[6] Y. Xiao, D. Ma, Y. Cheng, et al., "Effect of Labor Cost and Industrial Structure on the Development Mode Transformation of China's Industrial Economy", Emerging Markets Finance and Trade, 2019.

[7] M.J. Donate, E. R. Monterrubio, J.D. Sanchez de Pablo, et al., "Total quality management and high-performance work systems for social capital development Effects on company innovation capabilities", J. of Intellect. Capital, vol. 21, no. 1, pp. 87-114, 2019.

[8] A.A. Fedchenko, S.M. Poluhina, "Factor analysis of wage dynamics in Voronezh region', Urgent matters of accounting, economic analysis, and financial business control of organizations", pp. 281-285, 2017. Voronezh.

[9] G. Mills, S.-M. McKernan, C. Ratcliffe, et al., "First-Year Impacts on Savings and Economic Well-Being from the Assets for Independence Program Randomized Evaluation", J. of Consumer Affairs, vol. 53, no. SI 3, pp. 848-868, 2019.

[10] D.B. Willis, D.W. Hughes, K.A. Boys, "Economic growth through entrepreneurship: Determinants of self-employed income across regional economies", Papers in Reg. Sci., vol. 99, no. 1, pp. 73-95, 2019.

[11] B. Schalembier, B. Bleys, L.Van Ootegem, et al., "How relative income affects work hours preferences", Applied Econ., vol. 51, pp. 5545-5558, 2019.

[12] D. DiGioacchino, K. Sabani, S. Tedeschi, "Individual preferences for public education spending: Does personal income matter?", Econ. Modell., vol. 82, pp. 211-228, 2019.

[13] J.Y. Lin, "Structural change and poverty elimination", China Agricult. Econ. Rev., vol. 11, iss. 3, no. SI, pp. 452-459, 2019.

[14] R. Rodrigues, C.L. Butler, D. Guest, "Evaluating the employability paradox: When does organizational investment in human capital pay off?”, Int. J. of Human Resource Manag., 2019. 